\title{
COVIDReady2 study protocol: cross- sectional survey of medical student volunteering and education during the COVID-19 pandemic in the United Kingdom
}

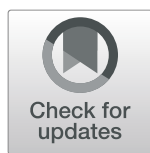

Matthew H. V. Byrne ${ }^{1 *}$ D, James Ashcroft ${ }^{2}$, Laith Alexander ${ }^{3}$, Jonathan C. M. Wan ${ }^{3}$, Anmol Arora ${ }^{4}$, Megan E. L. Brown ${ }^{5}$, Anna Harvey ${ }^{6}$, Andrew Clelland ${ }^{2}$, Nicholas Schindler ${ }^{7}$, Cecilia Brassett ${ }^{8}$, Rachel Allan ${ }^{9,10^{*}}$ and on behalf of the MedEd Collaborative

\begin{abstract}
Background: The coronavirus disease 2019 pandemic has led to global disruption of healthcare. Many students volunteered to provide clinical support. Volunteering to work in a clinical capacity was a unique medical education opportunity; however, it is unknown whether this was a positive learning experience or which volunteering roles were of most benefit to students.

Methods: The COVIDReady2 study is a national cross-sectional study of all medical students at medical schools in the United Kingdom. The primary outcome is to explore the experiences of medical students who volunteered during the pandemic in comparison to those who did not. We will compare responses to determine the educational benefit and issues they faced. In addition to quantitative analysis, thematic analysis will be used to identify themes in qualitative responses.

Discussion: There is a growing body of evidence to suggest that service roles have potential to enhance medical education; yet, there is a shortage of studies able to offer practical advice for how these roles may be incorporated in future medical education. We anticipate that this study will help to identify volunteer structures that have been beneficial for students, so that similar infrastructures can be used in the future, and help inform medical education in a non-pandemic setting.
\end{abstract}

Trial registration: Not Applicable.

Keywords: COVID-19, Coronavirus, SARS-CoV-2, Medical school, Medical education, Curriculum, Disaster medicine, Pandemic influenza, Service based learning, Volunteering

\footnotetext{
*Correspondence: mhvbyrne@doctors.org.uk; rachel.allan@phc.ox.ac.uk ${ }^{1}$ Nuffield Department of Surgical Sciences, University of Oxford, Old Rd, Headington, Oxford OX3 7LE, UK

${ }^{9}$ Nuffield Department of Primary Care Health Sciences, Medical Sciences Division, University of Oxford, Oxford, UK

Full list of author information is available at the end of the article
}

(C) The Author(s). 2021 Open Access This article is licensed under a Creative Commons Attribution 4.0 International License, which permits use, sharing, adaptation, distribution and reproduction in any medium or format, as long as you give appropriate credit to the original author(s) and the source, provide a link to the Creative Commons licence, and indicate if changes were made. The images or other third party material in this article are included in the article's Creative Commons licence, unless indicated otherwise in a credit line to the material. If material is not included in the article's Creative Commons licence and your intended use is not permitted by statutory regulation or exceeds the permitted use, you will need to obtain permission directly from the copyright holder. To view a copy of this licence, visit http://creativecommons.org/licenses/by/4.0/ The Creative Commons Public Domain Dedication waiver (http://creativecommons.org/publicdomain/zero/1.0/) applies to the data made available in this article, unless otherwise stated in a credit line to the data. 


\section{Background}

The coronavirus disease 2019 (COVID-19) pandemic has led to global disruption of healthcare services and medical education. In March 2020, the UK government announced that medical students were permitted to provide assistance during the pandemic [1]. Almost 7000 final year students obtained early provisional registration from the General Medical Council (GMC), filling 4662 new foundation interim year 1 (FiY1) doctor posts between April to July 2020. Students in other years volunteered to work in a wide range of roles to provide clinical support [2-5]. Similar initiatives have been organised internationally [6-8].

The UK Medical Schools Council advised against volunteering if it would disrupt a student's studies [9]. However, as many medical students had their medical studies and clinical placements interrupted, clinical volunteering work provided a unique medical educational experience to continue clinical skills development and gain additional skills, albeit in an unusual fashion. A survey of 440 final year medical students from 32 medical schools across the UK near the start of the pandemic indicated that students generally agreed that changing conventional placements due to the pandemic was necessary, but that they also felt less prepared for beginning their work as a doctor [10].

Our first COVIDReady study evaluated responses from 1145 students at 36/42 UK medical schools from 2nd May to 15th June 2020 (University of Cambridge Psychology Research Ethics Committee reference PRE.2020.040) [11]. Of these, $82.7 \%$ of students were willing to volunteer. The majority of students $(86.6 \%)$ felt that volunteering would benefit their education, and this was the strongest predictor of willingness to volunteer on multiple regression analysis (estimate $=0.35 \pm$ 0.03 , adjusted $P<0.001$ ). Thematic analysis of free text responses of anticipated issues when volunteering identified five themes: Education; Finances and Logistics; Professional Practice; Pressure to Volunteer; and Safety [11]. These themes broadly concur with the three main motivators towards joining the workforce early as identified by a GMC survey of 1448 final year students: learning gain, altruistic reasons and financial gain. The GMC also reported that a notable motivating factor was that volunteering would allow students to leave the house and socialize during lockdown conditions in which electives and holidays were cancelled [3]. Overall, the body of literature exploring student attitudes towards COVID-19 volunteering is maturing, but there is a notable shortage of studies aimed at students after they have actually participated in these roles [12-14]. One local study in Hamburg, Germany found that a majority of final year students $(n=40)$ working in hospitals during the pandemic felt that their help was not appreciated, that they were inadequately protected when treating COVID-19 patients, and that they did not acquire new skills [12]. Interestingly, in the same study, students in younger years who were volunteering $(n=17)$ generally felt appreciated, adequately protected and valued the learning experience. These findings suggest a complex interplay between the design of volunteering programmes during the pandemic and outcomes for students. Exploring these outcomes at a national scale remains a priority area of medical education research.

\section{Rationale for this study}

Early research has explored the uptake of volunteering opportunities by students but has not explored whether volunteering was a positive learning experience. This broadly reflects literature from previous pandemics and other disasters $[15,16]$. The COVIDReady2 study aims to build on previous work by assessing the educational benefit of volunteering and exploring the issues students faced while volunteering during the pandemic. We aim to answer the research questions: 'Was volunteering (in a paid or unpaid clinical capacity) during the pandemic a positive experience for medical students and what were the reasons for this? What issues did volunteer and nonvolunteer medical students encounter with volunteering during the pandemic?' We anticipate that this study will help to identify volunteer structures that have been beneficial for students, both so that similar infrastructures can be used in the future and to inform the structure of the non-pandemic clinical placements.

\section{Study objectives \\ Primary objective}

To explore the effect of volunteering during the pandemic on the medical education of students who volunteered, in comparison to those who did not volunteer.

\section{Secondary objectives}

To identify:

- Whether students would be willing to assume similar roles in a non-pandemic setting

- If students found the experience more or less beneficial than traditional hospital placements and the reasons for this

- Students' perceived benefits and disadvantages of volunteering

- Difference in perceived preparedness between students who did and did not volunteer for FY1 and the next academic year

To explore: 
- Issues associated with volunteering, including safety concerns

- Issues with role and competence

\section{Ethics}

Ethical approval for this study was obtained from the University of Oxford Interdivisional Medical Sciences Research Ethics Committee (Reference: R74003/RE001).

\section{Methods/design}

\section{Study design}

The COVIDReady2 study is a cross-sectional study of students and foundation year one (FY1) doctors who were medical students at UK medical schools between March 2020-June 2021 during the COVID-19 pandemic of 2020. The study will consist of an online survey disseminated to medical students and foundation doctors over a six-week period in Spring 2021.

\section{Study population}

Students and current FY1 doctors who were enrolled at a UK medical school at the start of the first UK lockdown for the COVID-19 pandemic (23rd March 2020), regardless of whether or not they volunteered during the pandemic.

\section{Inclusion criteria}

- Medical students at UK medical schools identified by the Medical Schools Council or FY1 doctors, regardless of whether or not they volunteered during the pandemic.

- Students and FY1 doctors must have been enrolled at a UK medical school at the start of the first UK lockdown for the COVID-19 pandemic (23rd March 2020).

- Participants must be aged 18 or older.

\section{Exclusion criteria}

- Students commencing their first year of medical school in the academic year 2020-2021.

\section{Survey development}

The survey was developed from existing literature following a systematic review of studies assessing willingness to volunteer during pandemics and disasters, the first COVIDReady study, and consultations with medical education specialists and medical students. A pilot study of 20 students was performed to ensure questions were unambiguous and establish face validity. The study was reviewed and approved by the UK Medical Schools Council Education Lead Advisory Group.

The survey will be hosted on Qualtrics XM (USA) [17]. The survey will be preceded by a description of the study, the research question, the contact details of the primary investigator, and a consent form. Data will be held on a secure server and email addresses, provided for optional follow up, deleted in two years. Once starting the survey, participants can withdraw consent by closing the browser and no data will be collected. As no identifiable data is collected participants will not be able to withdraw consent following completion of the survey, unless they have chosen to provide an email address at the end of the survey. The survey can be found in Appendix B.

\section{Data collection}

All medical schools will be contacted via their medical school office general enquiries email identified through a list provided by the Medical Schools Council [18]. This email will ask the medical schools to distribute a link to the survey to medical students and recently graduated medical students who are now working as FY1 doctors. We aim to recruit medical students from each UK medical school and FY1 doctors from each foundation school to help distribute the survey via social media. Messages will be posted at a maximal rate of once per week to prevent excessive messaging to students. After completion of the survey, participants are asked to share the survey with three other medical students to recruit additionally participants via a snowball approach.

\section{Sample size calculation and rationale}

A sample size calculation was performed, which showed that a total of 630 respondents are required to identify a significant 0.5 point (out of a 5-point Likert scale) increase in confidence or agreement with the statement 'I believe the period during the first lockdown (23 march 2020 to 4 July 2020) has benefited my medical education / career', considering stratification by year group.

This power calculation was performed with an alpha of 0.05 and a power of $80 \%$. Based on the results from the first COVIDReady study, the standard deviations of the anticipated Likert score means were conservatively set to 1 (out of 5), the ratio of students volunteering/ not-volunteering was estimated at 1:1, and the year group distribution of students was assumed to be equal.

\section{Data analysis plan}

STROBE guidelines for cross-sectional studies will be followed [19]. Data will be presented as descriptive statistics and comparisons between volunteer and nonvolunteer groups. For questions where qualitative responses are collected, we will conduct a thematic analysis using Braun and Clarke's reflexive approach to thematic analysis to code, sort, and analyse data [20]. Medical school names will be anonymised. 


\section{Expected outputs}

We anticipate that the results of this study will be published on a pre-print server and subsequently in a peerreviewed medical or scientific journal. We will submit this project to national and international conferences. Individuals involved in the recruitment of participants will be listed as collaborators under the group authorship: "MedEd Collaborative".

\section{Discussion}

Disruption caused to medical education by the ongoing COVID-19 pandemic has been well described; however, subsequent sequalae such as volunteering and early graduation remain under-discussed [21-23]. One way volunteering may benefit students is through increased service-based learning, a method of teaching wherein students perform and reflect on roles which intersect with their academic curriculum while also addressing community needs [24].

Arguments for adding service roles to curricula are grounded in educational theory, but due to medical school curricula constraints this has not been possible to achieve formally to date. The medical profession relies on experiential learning to refine situational judgement $[25,26]$. Lave and Wenger's Communities of Practice theory posits that learning is driven by novices working alongside experts and through the process of legitimate peripheral participation they move towards becoming experts themselves [27-29]. The theory was not intended to be a prescriptive model but rather a framework which may guide how to maximise knowledge sharing [30, 31]. Gaining experience as part of a clinical team and openly reflecting on it in informal settings can allow students to acquire tacit knowledge and personal growth which formal teaching cannot achieve [27]. In this way, even if service-learning roles do not directly offer knowledge-based teaching, they may improve selfconfidence, analytical abilities and communication skills [32]. The argument that integrated service roles may improve interpersonal skills is also supported by research concerning the educational principle of continuity, which suggests that spending extended periods of time as part of a medical team and following patient care throughout illness episodes may be beneficial [33]. However, it could also be contended that if service roles were not designed and integrated with the principle of continuity in mind, they may further fragment schedules and disrupt existing continuity, including examination timelines. In this way, it is possible that the effects of the pandemic and volunteering may have disrupted existing continuity within medical education. In the future, if such roles were integrated alongside conventional placements rather than disrupting them, they may introduce a fresh degree of continuity. This continuity is key to longitudinal integrated clerkships, a role in which students stay in the same place, with the same group and the same clinical team for extended periods of time [34].

Differences between conventional clinical placements and service roles are subtle, since they could involve students being in identical clinical environments but performing different activities. Whilst 'conventional' placements are heavily focused around students extracting learning potential from clinical environments, service roles involve balancing the objectives of additional stakeholders, such as the service provider [35]. O'Byrne et al. (2020) suggested that, whilst conventional placements can provide a stable learning environment, they may not provide students with the confidence and skills that might be required during a pandemic [36]. Conventional placements may be designed to focus on students maximising learning experience, and moving too far towards service provision may too be detrimental [32]. A concern that has been raised about service learning pertains to the heterogeneity between different placements, both in terms of the quality of the learning experiences and the grading of these learning experiences [37]. By contrast, standard clinical placements often revolve around predefined learning objectives which correspond to standardised assessment criteria [38]. This could be attributed to the principal of constructive alignment, which has been widely adopted in medical education in order to ensure that teaching and assessment are aligned with required learning objectives [39, 40].

Service-based learning is not equivalent to conventional volunteering, such as the type which is likely to have occurred during this pandemic. Service-based learning incorporates structured volunteer-based activities with pre-defined learning objectives and, crucially, reflective practice [32]. It has been postulated that whilst 'service-learning' may offer benefits to students, 'community service' may hinder their progress [32]. On this basis, it is plausible to argue that pandemic voluntary experiences could have been detrimental to medical education. The volunteering that may have occurred during the pandemic was likely to have been unstructured and independent of medical school learning objectives. Such volunteering is commendable, but may offer only incidental or occasional learning opportunities, rather than the clearly defined outcomes of conventional placements. During any future waves of COVID-19, as well as other potential disasters, it may be more beneficial to employ principles of constructive alignment by formalising volunteering roles as medical education opportunities, with defined outcomes and reflection [40, 41]. Prior to the pandemic, there were suggestions for increased provision of service-based learning beyond the clinical experience achieved through traditional clinical placements within UK medical curricula [32]. In the UK, 
these suggestions have been in the form of apprenticeship style final-years [42-44]. Though there has been some study of apprenticeships, there has been little empirical research able to recommend specific program structures and implementation steps for service-based learning, especially in earlier years of the medical curriculum $[24,45]$. However, early efforts to introduce service roles have shown promising results [46].

The year of medical school in which such programmes are implemented may be an independent factor in determining the success of the programme. For example, Elam et al. (2003) suggested that incorporating servicebased learning early in curricula may help in developing a community-based perspective towards clinical practice [47]. Working in voluntary roles under the supervision of nurses and allied healthcare professionals teaches the importance of interprofessional collaboration in delivering care, an early understanding of which can reap dividends in future years of medical training [48]. Importantly, there is only a limited body of evidence exploring practical considerations of volunteering roles. The early literature does generally concur that matching activities to learning goals and organising reflective learning and assessments can contribute to successful service learning structures [32]. This study aims to build on that body of literature by identifying volunteering structures which students found useful during the pandemic, as well as those that they did not.

The current study presents a unique opportunity for research whereby we are able to compare attitudes and perceived outcomes of students who volunteered with those who did not on a large scale. This will help to inform volunteering infrastructure during future waves of COVID-19, as well as informing the structure of current clinical placements and apprenticeships. Our findings may also have implications for re-structuring overseas medical electives where students volunteer without clearly defined curricular or learning objectives.

Our first COVIDReady study sought to explore the willingness to volunteering during the COVID-19 pandemic; COVIDReady2 now seeks to explore the educational impact of volunteering. In the short term, our findings may inform infrastructures for medical student volunteering in future waves of the COVID-19 pandemic. In the long term, our findings may inform the structure of clinical placements, electives, and apprenticeships. We anticipate future studies may explore the effects of volunteering on academic performance and career progression.

\section{Abbreviations}

COVID-19: Coronavirus disease 2019; FiY1: Foundation interim year one; FY1: Foundation year one; GMC: General Medical Council; NHS: National Health Service

\section{Supplementary Information}

The online version contains supplementary material available at https://doi. org/10.1186/s12909-021-02629-4.

Additional file 1. Appenfix B. Survey. ${ }^{*}$ Compulsory (only three questions).

\section{Acknowledgements}

We would like to thank the UK Medical Schools Council, the Royal Society of Medicine Student Members Group, IncisionUK, and the ADAPT Consortium for their support in developing this study.

MedEd Collaborative Authorship (all co-authors PubMed citable): Writing Group: Matthew HV Byrne, James Ashcroft, Laith Alexander, Jonathan C M Wan, Anmol Arora, Megan E L Brown, Anna Harvey, Andrew Clelland, Nicholas Schindler, Cecilia Brassett, Rachel Allan (Senior Author); Survey development group: Bryan Burford, Gillian Vance, Vigneshwar Raj, Soham Bandyopadhyay, Catherine Dominic, Siena Hayes, Aleksander Dawidziuk, Florence Kinder, Sanskrithi Sravanam, Michal Kawka, Adam Vaughan, Oliver P Devine, Aqua Asif, Jasper Mogg.

\section{Authors' contributions}

MHVB, JA, LA, JCMW were responsible for conceptualisation. MHVB, JA, LA, $J C M W, A A, M E L B, A H, A C, N S, C B, R A$ were responsible for writing the first draft. All authors (MHVB, JA, LA, JCMW, AA, MELB, AH, AC, NS, CB, RA, BB, GV, $\mathrm{VR}, \mathrm{SB}, \mathrm{CD}, \mathrm{SH}, \mathrm{AD}, \mathrm{FK}, \mathrm{SS}, \mathrm{MK}, \mathrm{AV}, \mathrm{OPD}, \mathrm{AqA}, J \mathrm{M})$ were responsible for designing the survey. All authors (MHVB, JA, LA, JCMW, AA, MELB, AH, AC, $N S, C B, R A, B B, G V, V R, S B, C D, S H, A D, F K, S S, M K, A V, O P D, A q A$, JM) were responsible for revisions. RA was responsible for supervision. All authors have read and approved the manuscript.

\section{Funding}

Nones.

Availability of data and materials

Not applicable.

\section{Declarations}

Ethics approval and consent to participate

Ethical approval for this study was obtained from the University of Oxford Medical Science Interdivisional Research Ethics Committee (Reference: R74003/RE001).

The survey will be preceded by a description of the study, the research question, the contact details of the primary investigator, and a consent form Once starting the survey, participants can withdraw consent by closing the browser and no data will be collected. As no identifiable data is collected participants will not be able to withdraw consent following completion of the survey, unless they have chosen to provide an email address at the end of the survey.

\section{Consent for publication}

Not applicable.

\section{Competing interests}

None

\section{Author details}

${ }^{1}$ Nuffield Department of Surgical Sciences, University of Oxford, Old Rd, Headington, Oxford OX3 7LE, UK. '2Department of Surgery, Addenbrooke's Hospital, University of Cambridge, Cambridge, UK. ${ }^{3}$ St Thomas' Hospital, London, UK. ${ }^{4}$ School of Clinical Medicine, University of Cambridge, Cambridge, UK. ${ }^{5}$ Health Professions Education Unit, Hull York Medical School, University of York, York, UK. 'King's College London GKT School of Medical Education, London, UK. 7 Paediatric Department, Norfolk and Norwich University Hospitals NHS Foundation Trust, Norwich, UK. ${ }^{8}$ Department of Physiology, Development and Neuroscience, University of Cambridge, Cambridge, UK. ${ }^{9}$ Nuffield Department of Primary Care Health Sciences, Medical Sciences Division, University of Oxford, Oxford, UK. ${ }^{10}$ Radcliffe Primary Care Building, Radcliffe Observatory Quarter, Woodstock Road, Oxford OX2 6GG, UK. 
Received: 9 March 2021 Accepted: 24 March 2021 Published online: 14 April 2021

\section{References}

1. Final-year medical students graduate early to fight Covid-19 | Coronavirus | The Guardian [Internet]. [cited 2021 Jan 22]. Available from: https://www. theguardian.com/world/2020/mar/20/final-year-medical-students-graduateearly-fight-coronavirus-covid-19

2. Kinder F, Harvey A. Covid-19: the medical students responding to the pandemic. BMJ. 2020;369:m2160.

3. General Medical Council. The state of medical education and practice in the UK 2020 [Internet]. [cited 2021 Jan 19]. Available from: https://www.gmc-uk. org/-/media/documents/somep-2020_pdf-84684244.pdf?la=en\&hash= F68243A899E21859AB1D31866CC54A0119E60291.

4. lacobucci G. Covid-19: medical schools are urged to fast-track final year students. BMJ. 2020;368:m1064

5. Allan $\mathrm{R}$, et al. Primary care student volunteering: lessons learned from the COVID-19 pandemic. BJGP. 2020; Available from: https://bjgp.org/content/ primary-care-student-volunteering-lessons-learned-covid-19-pandemic. Cited 2021 Jan 22.

6. Soled D, Goel S, Barry D, Erfani P, Joseph N, Kochis M, et al. Medical student mobilization during a crisis: lessons from a COVID-19 medical student response team. Acad Med. 2020;95(9):1384-7. https://doi.org/10.1097/ACM. 0000000000003401.

7. Schuiteman S, Ibrahim NI, Hammoud A, Kruger L, Mangrulkar RS, Daniel M. The role of medical student government in responding to COVID-19. Acad Med. 2021;96(1):62-7. https://doi.org/10.1097/ACM.0000000000003542.

8. Rasmussen S, Sperling P, Poulsen MS, Emmersen J, Andersen S. Medical students for health-care staff shortages during the COVID-19 pandemic. Lancet. 2020;395(10234):e79-80. https://doi.org/10.1016/S0140-6736(20)3 0923-5.

9. MSC issues Statement of Expectation for medical student volunteers in the NHS | Medical Schools Council [Internet]. [cited 2021 Jan 19]. Available from: https://www.medschools.ac.uk/news/msc-issues-statement-of-expectationfor-medical-student-volunteers-in-the-nhs

10. Choi B, Jegatheeswaran L, Minocha A, Alhilani M, Nakhoul M, Mutengesa E. The impact of the COVID-19 pandemic on final year medical students in the United Kingdom: a national survey. BMC Medical Education. 2020;20(1):206. https://doi.org/10.1186/s12909-020-02117-1.

11. Byrne M, Ashcroft J, Wan J, Alexander L, Harvey A, Schindler N, et al. COVID READY Study: Cross-sectional survey of medical students volunteering during the coronavirus pandemic (COVID-19) in the United Kingdom: Conference: ASiT / MedAll Virtual Surgical Summit 2020; 2020. https://doi. org/10.13140/RG.2.2.24986.67527.

12. Drexler R, Hambrecht JM, Oldhafer KJ. Involvement of medical students during the coronavirus disease 2019 pandemic: a cross-sectional survey study. Cureus. 2020;12(8):e10147. https://doi.org/10.7759/cureus.10147.

13. Patel J, Robbins T, Randeva H, de Boer R, Sankar S, Brake S, et al. Rising to the challenge: qualitative assessment of medical student perceptions responding to the COVID-19 pandemic. Clinical Medicine. 2020;20(6):e244-7. https://doi.org/10.7861/clinmed.2020-0219.

14. Astorp MS, Sørensen GVB, Rasmussen S, Emmersen J, Erbs AW, Andersen S. Support for mobilising medical students to join the COVID19 pandemic emergency healthcare workforce: a cross-sectional questionnaire survey. BMJ Open. 2020;10(9):e039082. https://doi.org/1 0.1136/bmjopen-2020-039082.

15. Herman B, Rosychuk RJ, Bailey T, Lake R, Yonge O, Marrie TJ. Medical students and pandemic influenza. Emerg Infect Dis. 2007;13(11):1781-3. https://doi.org/10.3201/eid1311.070279.

16. Rosychuk RJ, Bailey T, Haines C, Lake R, Herman B, Yonge O, et al. Willingness to volunteer during an influenza pandemic: perspectives from students and staff at a large Canadian university. Influenza Other Respir Viruses. 2008;2(2):71-9. https://doi.org/10.1111/j.1750-2659.2008.00042.x.

17. Qualtrics (Provo, Utah, USA). [cited 2021 Jan 19]. Available at: https://www. qualtrics.com

18. Medical schools | Medical Schools Council [Internet]. [cited 2021 Jan 19]. Available from: https://www.medschools.ac.uk/studying-medicine/medicalschools

19. STROBE Statement-Checklist of items that should be included in reports of cross-sectional studies [Internet]. 2007 [cited 2020 Jan 22]. Available from:
https://www.strobe-statement.org/fileadmin/Strobe/uploads/checklists/ STROBE_checklist_v4_cross-sectional.pdf

20. Braun V, Clarke V. Using thematic analysis in psychology. Qual Res Psychol. 2006;3(2):77-101. https://doi.org/10.1191/1478088706qp063oa.

21. Arora A, Solomou G, Bandyopadhyay S, Simons J, Osborne A, Georgiou I, et al. Adjusting to Disrupted Assessments, Placements and Teaching (ADAP T): a snapshot of the early response by UK medical schools to COVID-19. medRxiv. 2020;2020.07.29.20163907.

22. Lucey CR, Johnston SC. The transformational effects of COVID-19 on medical education. JAMA. 2020;324(11):1033-4. https://doi.org/10.1001/ja ma.2020.14136.

23. Macdougall C, Dangerfield P, Katz D, Strain W. The impact of COVID-19 on Medical education and Medical Students. How and when can they return to placements? MedEdPublish. 2020. https://doi.org/10.15694/mep.2020. 000159.1.

24. Stewart T, Wubbena ZC. A systematic review of service-learning in medical education: 1998-2012. Teach Learn Med. 2015;27(2):115-22. https://doi. org/10.1080/10401334.2015.1011647.

25. Sheng AY, Chu A, Biancarelli D, Drainoni M-L, Sullivan R, Schneider JI. A novel web-based experiential learning platform for medical students (learning moment): qualitative study. JMIR Med Educ. 2018;4(2):e10657. https://doi.org/10.2196/10657.

26. Armstrong E, Parsa-Parsi R. How can physicians' learning styles drive educational planning? Acad Med. 2005;80(7):680-4. https://doi.org/10.1097/ 00001888-200507000-00013.

27. Li LC, Grimshaw JM, Nielsen C, Judd M, Coyte PC, Graham ID. Evolution of Wenger's concept of community of practice. Implement Sci. 2009;4(1):11. https://doi.org/10.1186/1748-5908-4-11.

28. Lave J, Wenger E. Situated Learning: Legitimate Peripheral Participation. Cambridge: Cambridge University Press; 1991.

29. Buckley $H$, Steinert $Y$, Regehr $G$, Nimmon L. When I say ... community of practice. Med Educ. 2019;53(8):763-5. https://doi.org/10.1111/medu.13823.

30. O'Brien BC, Battista A. Situated learning theory in health professions education research: a scoping review. Adv in Health Sci Educ. 2020;25(2): 483-509. https://doi.org/10.1007/s10459-019-09900-w.

31. Ranmuthugala G, Plumb JJ, Cunningham FC, Georgiou A, Westbrook J, Braithwaite J. How and why are communities of practice established in the healthcare sector? A systematic review of the literature. BMC Health Serv Res. 2011;11(1):273. https://doi.org/10.1186/1472-6963-11-273.

32. Stewart T, Wubbena Z. An overview of infusing service-learning in medical education. Int J Med Educ. 2014;5:147-56. https://doi.org/10.5116/ijme.53ae.c907.

33. Hirsh DA, Ogur B, Thibault GE, Cox M. "Continuity" as an organizing principle for clinical education reform. N Engl J Med. 2007;356(8):858-66. https://doi.org/10.1056/NEJMsb061660.

34. Norris TE, Schaad DC, DeWitt D, Ogur B, Hunt DD, Clerkships members of the $C$ of LI. Longitudinal integrated clerkships for medical students: an innovation adopted by medical schools in Australia, Canada, South Africa, and the United States. Acad Med. 2009;84(7):902-7. https://doi.org/10.1 097/ACM.0b013e3181a85776.

35. Seifer SD. Service-learning: community-campus partnerships for health professions education. Acad Med. 1998;73(3):273-7. https://doi.org/10.1097/ 00001888-199803000-00015.

36. O'Byrne L, Gavin B, McNicholas F. Medical students and COVID-19: the need for pandemic preparedness. J Med Ethics. 2020;46(9):623-6. https://doi.org/1 0.1136/medethics-2020-106353.

37. Hunt JB, Bonham C, Jones L. Understanding the goals of service learning and community-based medical education: a systematic review. Acad Med. 2011;86(2):246-51. https://doi.org/10.1097/ACM.0b013e3182046481.

38. Assessment in undergraduate medical education [Internet]. General Medical Council. 2011 [cited 2021 Jan 22]. Available from: https://www.gmc-uk.org/-/ media/documents/Assessment_in_undergraduate_medical_education_ guidance_0815.pdf_56439668.pdf

39. Barrow M, McKimm J, Samarasekera DD. Strategies for planning and designing medical curricula and clinical teaching. Southeast Asian J Med Educ. 2010;4(1):2-8.

40. Biggs J. Enhancing teaching through constructive alignment. High Educ. 1996;32(3):347-64. https://doi.org/10.1007/BF00138871.

41. Wise J. Covid-19: risk of second wave is very real, say researchers. BMJ. 2020; 369:m2294.

42. Nabavi N. Apprenticeship model would better prepare medical students for practice, says RCP. BMJ. 2021;372:n65. 
43. Double or quits: a blueprint for expanding medical school places [Internet]. RCP London. 2021 [cited 2021 Jan 22]. Available from: https://www. rcplondon.ac.uk/projects/outputs/double-or-quits-blueprint-expandingmedical-school-places

44. Foundation programme review [Internet]. Health Education England. 2019 [cited 2021 Jan 22]. Available from: https://www.hee.nhs.uk/our-work/ doctors-training/foundation-review

45. Wells SE, Bullock A, Monrouxe LV. Newly qualified doctors' perceived effects of assistantship alignment with first post: a longitudinal questionnaire study. BMJ Open. 2019;9(3):e023992. https:/doi.org/10.1136/bmjopen-2018-023992.

46. Buckner AV, Ndjakani YD, Banks B, Blumenthal DS. Using service-learning to teach community health: the Morehouse School of Medicine Community health course. Acad Med. 2010;85(10):1645-51. https://doi.org/10.1097/ACM. 0b013e3181f08348.

47. Elam CL, Sauer MJ, Stratton TD, Skelton J, Crocker D, Musick DW. Service learning in the medical curriculum: developing and evaluating an elective experience. Teach Learn Med. 2003;15(3):194-203. https://doi.org/10.1207/S1 5328015TLM1503_08.

48. Buckland R. Medical student volunteering during COVID-19: lessons for future interprofessional practice. J Interprofessional Care. 2020;34(5):679-81. https://doi.org/10.1080/13561820.2020.1822790.

\section{Publisher's Note}

Springer Nature remains neutral with regard to jurisdictional claims in published maps and institutional affiliations.

Ready to submit your research? Choose BMC and benefit from:

- fast, convenient online submission

- thorough peer review by experienced researchers in your field

- rapid publication on acceptance

- support for research data, including large and complex data types

- gold Open Access which fosters wider collaboration and increased citations

- maximum visibility for your research: over $100 \mathrm{M}$ website views per year

At $\mathrm{BMC}$, research is always in progress.

Learn more biomedcentral.com/submissions 